Pediat. Res. 1: 443-451 (1967)

Fetus hyperglycemia

placenta gluconeogenesis

glucose space glycogen, liver

\title{
Glucose Metabolism in the Fetus in Utero: The Effect of Maternal Fasting and Glucose Loading in the Rat
}

\author{
C.J.GOodneR ${ }^{[25]}$ and Donna J.Thompson \\ The Robert H.Williams Laboratory for Clinical Investigation, Department of Medicine, King County Hospital, \\ and the University of Washington School of Medicine, Seattle, Washington, USA
}

Extract

Pregnant rats during the last 3 days of gestation were fasted 16 hours, anesthetized and infused with glucose-U-C ${ }^{14}$ for two hours following a loading dose of labeled glucose. Rats infused with tracer only were compared with glucose-loaded rats. The volume of distribution for glucose was $28 \%$ in the fasted rats and increased to $50 \%$ of body weight with glucose loading. Hepatic glucose production was $1.2 \mathrm{mg} / \mathrm{min} / 300 \mathrm{~g}$ body weight in the fasted rats. This value was depressed to 0.32 with glucose loading. Comparison of maternal and fetal plasma after the two-hour infusion showed that the concentration of glucose in fetal plasma equaled the maternal in fasting rats and paralleled maternal hyperglycemia with a gradient (maternal to fetal) of 1.22 in the glucose-loaded rats. In the fasted rats, the specific activity of fetal plasma glucose was less than half that of maternal plasma glucose, indicating that unlabeled glucose was being produced within the conceptus. By contrast, the specific activities were more nearly equal in the glucose-loaded rats, showing that maternal plasma glucose was the primary source of fetal plasma glucose during hyperglycemia. The glycogen concentrations of fetal liver and placenta were not altered by glucose loading. The degree of labeling of glycogen was very small in fetal liver and placenta in fasting rats, while glucose loading increased the specific activity of glycogen in these two organs but the quantitative change in glycogen remained small compared to the total glycogen stores. However, with glucose loading, the incorporation of radioglucose into maternal liver glycogen reached $31 \%$ of the liver glycogen store.

From these data it is concluded that under conditions of fasting, the fetal liver contributes to the fetal plasma glucose through gluconeogenesis in preference to glycogenolysis, while in the presence of maternal hyperglycemia, fetal gluconeogenesis is reduced and glycogen synthesis in fetal liver is accelerated.

\section{Speculation}

During fasting, a competition may develop for gluconeogenetic precursors between the maternal liver, the fetal liver and the growing fetal tissues. Because of such a competition, prolonged fasting or protein malnutrition could result in either reduced availability of fetal glucose or limitation of protein synthesis or both. During short periods of fasting, the store of glycogen in the fetal liver was neither mobilized nor significantly increased by synthesis from glucose, while with glucose loading, net synthesis increased. These data suggest that accumulation of fetal liver glycogen occurs as a stepwise cycle with net synthesis occurring only during feeding and relative retardation of glycogenolysis predominating during fasting. 


\section{Introduction}

Measurements of maternal and fetal plasma glucose concentrations at caesarian section have shown that the fetal plasma glucose generally parallels the maternal plasma glucose with a maternal to fetal concentration gradient $[3,13]$. Present evidence suggests that maternal glucose is actively transported across the placenta or crosses by facilitated diffusion [23]. Possible mechanisms for regulation of plasma glucose by the fetus in utero have not been extensively studied. Morphologic evidence for increased pancreatic beta cell activity in the fetus in response to hyperglycemia has been presented [15].

It has been established that fetal glycogen stores are dependent upon pituitary and adrenal hormones [14] and that maternal starvation [18] and fetal anoxia [6] will deplete fetal glycogen. With these exceptions, most of the concepts about pathways of fetal glucose metabolism have been inferred from in vitro study of fetal tissues [8]. Such studies have not provided the dynamic information needed to understand the pathogenetic sequence in disorders of fetal-maternal metabolism such as diabetes or neonatal hypoglycemia. The present study is an attempt to study regulation of fetal glucose metabolism in the intact pregnant rat under basic conditions of glucose loading and glucose deprivation.

\section{Methods}

\section{Animals}

Pregnant rats of the Sprague-Dawley strain were obtained at midgestation from a commercial breeding farm $^{1}$ and maintained on Purina rat chow. Near-term animals were selected for study by palpation of fetal size. At sacrifice, maternal body weights ranged from 255-375 g and average fetal weights ranged from 2.33 to $6.30 \mathrm{~g}$. Studies were done after a 16-hour fast. Free access to water was permitted until anesthesia.

\section{Glucose Kinetics}

Rats were anesthetized with pentobarbital (3 $\mathrm{mg} /$ $100 \mathrm{~g}$ body weight injected intraperitoneally). Light surgical anesthesia was then maintained by repeating smaller doses of pentobarbital when necessary. A No. 25 needle was placed in a surgically exposed femoral vein and connected with polyethylene tubing to a motordriven syringe pump. Uniformly labelled $\mathrm{C}^{14}$ glucose ${ }^{2}$ was given as a loading dose $(4.2 \mu \mathrm{c}$ in $1.0 \mathrm{ml}$ normal

${ }^{1}$ Northwest Rodent Farms, Pullman, Washington.

${ }^{2}$ Obtained from New England Nuclear Corp., Boston, Massachusetts. Specific activity $83 \mu \mathrm{c} / \mathrm{mg}$. saline) followed by constant infusion for two hours $(5.0 \mu \mathrm{c}$ and $1.2 \mathrm{ml} / \mathrm{h})$. The pump delivered the solution with an error of $\pm 1.4 \%$ at the rate used in these studies, $1.2 \mathrm{ml} / \mathrm{h}$.

Blood samples were collected from the severed tip of the tail at $30,60,90$ and 115 minutes after the start of infusion. Brisk flow was obtained by warming the tail with a small lamp during the infusion. The tail blood samples were collected directly into chilled, siliconized tubes containing dried heparin. Plasma was separated at $4^{\circ}$ for later determination of the specific activity of glucose. After 120 minutes of infusion, the abdomen was opened and the aorta entered with a needle. The arterial blood volume was quickly withdrawn into an heparinized syringe. The uterus was then rapidly removed by severing its blood supply. One operator removed the maternal liver and quickly froze it in powdered solid carbon dioxide, while the other opened the uterus and removed two fetuses. Both operators then began to wipe amniotic fluid from viable fetuses, snip their neck vessels, and collect fetal blood in chilled tubes. When free flow stopped, the fetal abdomen was opened and the entire fetal liver removed. The fetal liver and the placenta were quickly frozen. This process was repeated by each operator until each had separately collected and pooled blood and organs from three fetuses. Finally, the number of fetuses was recorded and three representative fetuses were collected and frozen for determination of average fetal weight.

The two fetal blood samples each ranged in volume from 0.4 to $1.0 \mathrm{ml}$ depending upon fetal weight. The frozen placentas, fetal livers and maternal liver were weighed and then analyzed for glycogen by the method of Good [10]. From the weights of pooled organs, the glycogen concentration, the average fetal weight, and the total number of fetuses, organ weights and glycogen contents could be calculated for average individual fetuses and for the total fetal pool. The total content of maternal liver glycogen was similarly calculated. The final hydrolysate of purified glycogen was neutralized, dried, and counted for radioactivity, and its specific activity calculated [11].

The concentration of glucose in maternal and fetal plasma and in the infusion solution was determined with a glucose oxidase method performed on deproteinized micro filtrates. For determination of specific activity, $20 \mu \mathrm{l}$ aliquots of maternal and fetal plasma and the infusion solution were quantitatively applied to individual 1 by 18 inch strips of Whatman No. 1 filter paper. The strips were developed by descending chromatography in pyridine, acetic acid, isopropanol water $(8: 18: 4)$ for 16-18 hours. After drying, the chromatograms were placed in contact with X-ray film and stored in cassettes for two weeks. By direct comparison with the developed radioautograms, the glucose spots 
were cut from the paper strips and placed in liquid scintillator for determination of radioactivity in a TriCarb Liquid Scintillation Counter (Packard Co.). Specific activity was expressed as GPM per $\mu$ g glucose.

With these techniques, the following data were obtained for calculation of glucose kinetics in the pregnant rat: 1 . the concentration and specific activity of glucose in maternal plasma at four points during constant infusion of trace-labeled glucose-these data served to document the degree to which equilibrium of tracer had been achieved; 2 . the concentration and specific activity of glucose in maternal plasma and duplicate pools of fetal plasma at sacrifice after two hours of infusion of glucose $\mathrm{C}^{14} ; 3$. the specific activity and rate of delivery of glucose in the constant infusion; and 4. the contents and specific activities of tissue glycogen in maternal liver, placenta and fetal liver at the end of two hours of infusion of labeled glucose.

A total of 15 rats were studied. Ten rats received only tracer glucose in the infusion for calculation of fasting glucose kinetics while 5 received a glucose load along with the tracer infusion (the loading and infusion solutions contained $30 \mathrm{~g}$ glucose per $100 \mathrm{ml}$ ).

\section{Calculations}

The methods of calculating glucose space and glucose entry after two hours of infusion are based upon the following assumptions: 1. The labeled glucose has distributed throughout the exchangeableglucosespace. 2. A steady state prevails. 3. Under these conditions, glucose entry equals glucose utilization [19].

Under these conditions, the size of the glucose pool, $P_{G}$, can be calculated from the dilution of the priming dose in plasma at steady state.

$\mathrm{P}_{\mathrm{G}}(\mathrm{mg})=\frac{\mathrm{CPM} / \mathrm{ml} \text { infusion (Priming dose } 1.0 \mathrm{ml} \text { ) }}{\mathrm{CPM} / \mathrm{mg} \text { glucose in plasma }}$

The volume of distribution for glucose $V_{G}$ in $\mathrm{ml}$ was calculated from the plasma glucose concentration and the pool size.

$\mathrm{V}_{\mathrm{G}}=\frac{\mathrm{P}_{\mathrm{G}} \mathrm{mg}}{\mathrm{mg} / \mathrm{ml} \text { in plasma }}$

This volume was also expressed as percent body weight.

Percent body weight $=\overline{\text { Body weight in grams }}$

The rate of entry of glucose $G$ was calculated from the rate of infusion of glucose and the dilution of its specific activity by unlabeled glucose within the glucose pool.

$\mathrm{G}$ in $\mu \mathrm{g} / \mathrm{min}=\frac{\mathrm{GPM} / \mu \mathrm{g} \text { infusion }}{\mathrm{GPM} / \mu \mathrm{g} \text { plasma }} \times \begin{aligned} & \text { rate of infusion } \\ & \text { in } \mu \mathrm{g} / \mathrm{min}\end{aligned}$

Hepatic glucose production $\mathrm{G}_{\mathrm{H}}$ was calculated as the rate of entry less the contribution of the infusion.

$\mathrm{G}_{\mathrm{H}} \mu \mathrm{g} / \mathrm{min}=\mathrm{G}$-rate of infusion $(\mu \mathrm{g} / \mathrm{min})$

For ease of comparison between animals, hepatic glu- cose production was expressed as $\mu \mathrm{g} / \mathrm{min} / 300 \mathrm{~g}$ body weight, $\mathrm{G}_{\mathrm{H}}(300)$.

$\mathrm{G}_{\mathrm{H}}(300)=\mathrm{G}_{\mathrm{H}} \times \frac{300}{\text { body weight }}$

Results

Figure 1 presents the concentration and specific activity (SA) of glucose in maternal plasma at four intervals during the two-hour infusions. In both experimental groups, the mean values for specific activity rose steadily during the infusion rather than behaving ideally for the method; that is, remaining constant. The concentration of glucose in maternal plasma also rose slightly in the fasted and glucose-loaded groups. The relative changes in concentration and specific activity of glucose during the last hour of the infusion were not large in either case. The greatest relative change occurred in the specific activity of plasma glucose in the fasting group (a rise of $12 \%$ during the period between 60 and 120 minutes). The effect of ignoring this degree of nonequilibrium upon the conclusions of the study was assessed with the general equation of STEELE et al. [19] and proved to be unimportant; therefore, the simpler
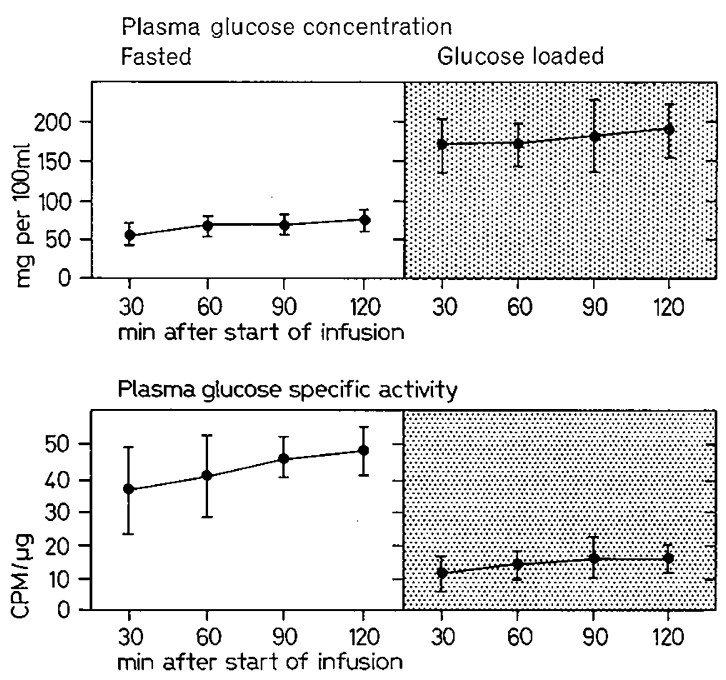

Fig. 1. Pregnant rats during the last three days of gestation were given a loading dose and then infused with glucose-U-C $\mathrm{C}^{14}$ at a constant rate for two hours. The concentration and specific activity of maternal plasma glucose were determined at 30-minute intervals on blood samples obtained from the tail. The rats were fasted for 16 hours before the experiment. The glucoseloaded group received $30 \%$ glucose in the infusion. Brackets denote two standard errors of the mean. Fasted group, 10 rats; glucose-loaded, 5 rats. 
calculations based upon the assumption of strict steady state were used in compiling the data. The volumes of distribution of glucose $\left(V_{G}\right)$, the glucose entry rates $(G)$, the corrected hepatic glucose outputs, $\mathrm{G}_{\mathrm{H}}(300)$, and the glucose pools $\left(\mathrm{P}_{\mathrm{G}}\right)$ are summarized in table $\mathrm{I}$. The volume of distribution averaged $27.6 \%$ of body weight in the fasted group, and rose significantly to $50.4 \%$ with glucose loading. The value for $\mathrm{V}_{\mathrm{G}}$ in the fasting group compares favorably with the value of $29 \%$ in nonpregnant rats reported by Depocas using a similar method [9]. The hepatic glucose production in the fasting group averaged $1.2 \mathrm{mg} / \mathrm{min}$ and is similar to that reported by DEPOCAs in nonpregnant fasted rats ( $1.56 \mathrm{mg} / \mathrm{min} / 300 \mathrm{~g} \mathrm{rat}$ ). In the glucose-loaded animals, hepatic glucose output was reduced to $0.32 \mathrm{mg} /$ min. The total glucose pool averaged $63.8 \mathrm{mg}$ in the fasted group and $292 \mathrm{mg}$ in the glucose-loaded group. The larger volume of distribution and glucose pool and the smaller hepatic glucose output in the glucose-loaded rats were all significantly different from the corresponding values in the fasted rats.

\section{Fetal Glucose Kinetics}

Comparisons of the maternal and fetal plasma glucose concentration and specific activity in the three experimental groups are listed in table II. In the fasted animals, the concentrations of glucose were equal in maternal and fetal plasma. In the glucose-loaded group, the fetus shared the maternal hyperglycemia. However, the fetal plasma glucose was lower than that of the maternal plasma glucose by a relatively constant ratio averaging 1.22 .

The specific activity of fetal plasma glucose was depressed in the fasted group, while in the glucose-loaded animals, the specific activities of glucose in maternal and fetal plasma were nearly equal and both approached the specific activity of the infusion solution. Assuming that the glucose in the fetal compartment had a

Table I. Summary of studies of glucose kinetics $^{1}$ in pregnant rats during the last 3 days of gestation

\begin{tabular}{|c|c|c|c|c|c|c|c|c|c|c|}
\hline \multirow[b]{2}{*}{ Rat No. } & \multirow[b]{2}{*}{$\begin{array}{l}\text { Body wt } \\
\mathrm{g}\end{array}$} & \multirow[b]{2}{*}{$\begin{array}{l}\text { t. Fetal wt } \\
\mathrm{g}\end{array}$} & \multirow[b]{2}{*}{$\begin{array}{l}\text { No. of } \\
\text { fetuses }\end{array}$} & \multicolumn{2}{|c|}{$\begin{array}{c}\text { Glucose space, } \\
\text { volume of } \\
\text { distribution }\end{array}$} & \multicolumn{2}{|c|}{ Glucose entry } & \multirow{2}{*}{$\begin{array}{l}\text { Glucose } \\
\text { pool } \\
\mathrm{P}_{\mathrm{G}} \\
\mathrm{mg}\end{array}$} & \multicolumn{2}{|c|}{ Glucose infusion } \\
\hline & & & & $\mathrm{V}_{\mathrm{G}} \mathrm{ml}$ & $\begin{array}{l}\mathrm{V}_{\mathrm{G}} \\
\% \mathrm{BW}\end{array}$ & $\begin{array}{l}\mathrm{G} \\
\mu \mathrm{g} / \mathrm{min}\end{array}$ & $\begin{array}{l}\mathrm{G}_{\mathrm{H}}(300) \\
\mu \mathrm{g} / \mathrm{min}\end{array}$ & & $\begin{array}{l}\mathrm{SA} \\
\mathrm{CPM} / \mu \mathrm{g}\end{array}$ & $\begin{array}{l}\text { Rate } \\
\mu \mathrm{g} / \mathrm{min}\end{array}$ \\
\hline \multicolumn{11}{|c|}{ A. Fasted } \\
\hline 1 & 360 & 3.67 & 15 & 66.1 & 18.4 & 1,073 & 894 & 53.5 & $3.56 \times 10^{4}$ & 1.28 \\
\hline 2 & 320 & 4.96 & 10 & 90.8 & 28.4 & 1,071 & 1,004 & 53.6 & $5.68 \times 10^{4}$ & 0.98 \\
\hline 3 & 285 & 4.51 & 11 & 64.6 & 22.7 & 1,213 & 1,277 & 60.7 & $3.59 \times 10^{4}$ & 1.59 \\
\hline 4 & 325 & 3.41 & 16 & 64.3 & 19.8 & 1,197 & 1,104 & 59.8 & $4.02 \times 10^{4}$ & 1.33 \\
\hline 5 & 370 & 4.65 & 17 & 157 & 42.4 & 1,915 & 1,553 & 95.8 & $4.74 \times 10^{4}$ & 1.37 \\
\hline 6 & 340 & 4.81 & 14 & 75.9 & 22.3 & 1,311 & 1,157 & 58.4 & $5.67 \times 10^{4}$ & 1.01 \\
\hline 7 & 255 & 4.21 & 13 & 73.4 & 28.8 & 1,136 & 1,336 & 51.4 & $5.36 \times 10^{4}$ & 1.01 \\
\hline 8 & 330 & 5.12 & 9 & 98.5 & 29.8 & 1,420 & 1,290 & 70.9 & $3.79 \times 10^{4}$ & 1.34 \\
\hline 9 & 340 & 4.81 & 14 & 109 & 32.0 & 1,395 & 1,230 & 69.7 & $3.79 \times 10^{4}$ & 1.37 \\
\hline 10 & 340 & 5.16 & 12 & 106 & 31.4 & 1,290 & 1,150 & 64.7 & $3.79 \times 10^{4}$ & 1.37 \\
\hline Mean & 327 & 4.53 & 13 & & 27.6 & & 1,200 & 63.8 & & \\
\hline$\pm \mathrm{SD}$ & \pm 31 & \pm 0.59 & \pm 6 & & \pm 6.8 & & \pm 179 & \pm 12.5 & & \\
\hline
\end{tabular}

B. Glucose loaded

\begin{tabular}{lrrrrrrrrrr}
\hline 11 & 310 & 3.87 & 11 & 102 & 32.7 & 5,040 & -58 & 251 & 21.2 & 5,100 \\
12 & 370 & 6.30 & 12 & 245 & 66.2 & 5,950 & 511 & 301 & 20.8 & 5,318 \\
13 & 360 & 5.24 & 9 & 129 & 35.8 & 5,500 & 00 & 238 & 11.6 & 5,500 \\
14 & 335 & 2.52 & 14 & 231 & 69.2 & 6,300 & 717 & 346 & 11.6 & 5,500 \\
15 & 350 & 5.73 & 10 & 169 & 48.0 & 6,000 & 429 & 321 & 11.6 & 5,500 \\
Mean & 345 & 4.73 & 11 & & $50.4^{2}$ & & $320^{2}$ & $292^{2}$ & & \\
\pm SD & \pm 22 & \pm 0.43 & \pm 3 & & \pm 10.7 & & \pm 300 & \pm 37 & & \\
\hline
\end{tabular}

${ }^{1}$ After a 16-hour fast, all animals were infused with glucose-U-G ${ }^{14}$ for 2 hours. To 5 animals a glucose load was given together with the labeled glucose. See text for conditions and abbreviations.

${ }^{2} \mathrm{p}<0.001$, fasted versus glucose-loaded 
turnover time less than the period of infusion, it may be concluded that the maternal plasma was not the sole source of fetal plasma glucose in the fasted group. In this group, on the basis of specific activity dilution in the fetal plasma, assuming steady state conditions, it can be calculated that the maternal plasma glucose contributed about $60 \%$ of the fetal glucose pool and that the other $40 \%$ was derived from gluconeogenetic or glycogenolytic pathways within the conceptus. By contrast, in the glucose-loaded rats, in which the specific activity of glucose was more nearly equal in maternal and fetal plasma, it is estimated that $85 \%$ of the glucose in fetal plasma was derived from maternal plasma glucose and only $15 \%$ originated within the conceptus. Since uterine blood flow and transplacental flux of glucose are unknown, the actual rate of glucose entry and of intrafetal glucose production cannot be determined from these data ${ }^{3}$.

The estimated size of the fetal glucose pool in the two groups is listed in table II. These data have been calculated assuming a fetal glucose volume of distribution of $30 \%$ body weight. If this assumption is valid, the fetal glucose pool represents about one fifth the total glucose pool in the pregnant rat as determined by glucose kinetics from the maternal circulation.

The source of unlabeled glucose produced within the fetus during these experiments could be either glu-

${ }^{3}$ The values for the relative fraction of glucose produced within the fetus, as calculated in table II, may be an underestimation of the actual fraction produced within the fetus, because recycling of label within the conceptus would tend to raise the specific activity of fetal glucose. Likewise, recycling of glucose within the maternal space would tend to raise the specific activity of precursors for gluconeogenesis in both maternal and fetal plasma, thereby causing underestimation of gluconeogenesis in both compartments.

Table II. The concentration and specific activity of glucose in maternal and fetal plasma after infusion of labeled glucose for two hours

\begin{tabular}{|c|c|c|c|c|c|c|c|c|c|}
\hline \multirow{3}{*}{ Rat No } & \multirow{3}{*}{$\begin{array}{l}\text { Mater- } \\
\text { nal } \\
\text { plasma } \\
(\mathrm{MP}) \\
\mathrm{mg} \%\end{array}$} & \multicolumn{2}{|c|}{ Plasma glucose } & \multicolumn{2}{|c|}{ Specific activity glucose } & \multicolumn{4}{|c|}{ Glucose, fetal plasma } \\
\hline & & $\begin{array}{l}\text { Fetal } \\
\text { plasma } \\
(\mathrm{FP})\end{array}$ & $\begin{array}{l}\text { Ratio } \\
\mathrm{MP} / \mathrm{FP}\end{array}$ & $\begin{array}{l}\text { Maternal } \\
\text { plasma }\end{array}$ & $\begin{array}{l}\text { Fetal } \\
\text { plasma }\end{array}$ & $\begin{array}{l}\text { Estimated } \\
\text { fetal, } \mathrm{ml}\end{array}$ & $\begin{array}{l}\text { Estimated } \\
\text { fetal, mg }\end{array}$ & $\begin{array}{l}\text { d Percent } \\
\text { from }\end{array}$ & $\begin{array}{l}\text { Percent } \\
\text { from }\end{array}$ \\
\hline & & $\mathrm{mg} \%$ & & $\mathrm{CPM} / \mu \mathrm{g}$ & $\mathrm{CPM} / \mu \mathrm{g}$ & $\mathrm{V}_{\mathrm{G}}$ & $P_{G}$ & MP & $\mathrm{FP}$ \\
\hline \multicolumn{10}{|c|}{ A. Fasted } \\
\hline 1 & 81 & 65 & 1.24 & 42.5 & 21.5 & 16.5 & 10.7 & 51 & 49 \\
\hline 2 & 59 & 78 & 0.76 & 52.0 & 26.3 & 14.9 & 11.6 & 51 & 49 \\
\hline 3 & 92 & 87 & 1.06 & 47.0 & 30.8 & 14.9 & 12.9 & 65 & 35 \\
\hline 4 & 93 & 107 & 0.87 & 44.7 & 20.1 & 16.5 & 17.5 & 45 & 55 \\
\hline 5 & 61 & 66 & 0.92 & 33.9 & 16.4 & 23.7 & 15.6 & 48 & 52 \\
\hline 6 & 77 & 78 & 0.99 & 49.2 & 30.7 & 20.2 & 15.8 & 63 & 37 \\
\hline 7 & 70 & 64 & 1.09 & 52.8 & 34.4 & 16.5 & 10.5 & 65 & 35 \\
\hline 8 & 72 & 73 & 0.99 & 35.8 & 19.4 & 13.8 & 16.0 & 54 & 46 \\
\hline 9 & 64 & 70 & 0.91 & 37.2 & 21.8 & 20.2 & 14.7 & 59 & 41 \\
\hline 10 & 61 & 55 & 1.11 & 40.1 & 32.3 & 18.6 & 9.1 & 81 & 19 \\
\hline Mean & 73 & 74 & 0.99 & 43.5 & 25.4 & 17.6 & 13.4 & 58 & 42 \\
\hline$\pm \mathrm{SD}=$ & \pm 13 & \pm 14 & \pm 0.13 & \pm 6.7 & \pm 6.1 & \pm 2.9 & \pm 2.7 & \pm 10 & \pm 10 \\
\hline \multicolumn{10}{|c|}{ B. Glucose loaded } \\
\hline 11 & 246 & 191 & 1.29 & 21.5 & 13.7 & 12.6 & 24.1 & 64 & 36 \\
\hline 12 & 122 & 94 & 1.30 & 18.6 & 14.1 & 22.8 & 21.4 & 76 & 24 \\
\hline 13 & 184 & 163 & 1.13 & 10.9 & 10.6 & 14.1 & 23.0 & 97 & 3 \\
\hline 14 & 150 & 125 & 1.20 & 9.2 & 8.1 & 10.5 & 13.1 & 88 & 12 \\
\hline 15 & 190 & 158 & 1.20 & 9.7 & 9.5 & 17.1 & 27.0 & 98 & 2 \\
\hline Mean & 178 & 146 & 1.22 & 14.8 & 11.2 & 15.4 & 21.7 & 85 & 15 \\
\hline$\pm \mathrm{SD}=$ & \pm 31 & \pm 33 & \pm 0.064 & \pm 2.8 & \pm 2.3 & \pm 4.3 & \pm 4.7 & \pm 13 & \pm 13 \\
\hline
\end{tabular}


coneogenesis or glycogenolysis from preformed glycogen stores. In an attempt to separate these possibilities, the concentration and degree of labelling of glycogen stores in maternal liver, placenta and fetal liver were examined.

Glycogen Stores in Maternal Liver, Placenta and Fetal Liver

During the last three days of gestation in the rat, fetal liver glycogen rises to high levels [18]. Figure 2 illustrates the relation between percent glycogen in fetal liver and gestational age in days or grams fetal weight in a group of fed animals of the same strain sacrificed by similar techniques. The average fetal weight and percent liver glycogen of animals in the two experimental groups are denoted by the circles labeled $\mathrm{F}$ for the fasted group and $\mathrm{Gl}$ for the glucoseloaded group. The individual organ weights and glycogen contents are listed in table III. From the data in figure 2 , it is concluded that the glycogen concentration in fetal liver did not differ from the expected normal range in either of the experimental groups.

The relatively high concentration of glycogen in fetal liver results in a total glycogen store in fetal liver equal to or greater than that in maternal liver, although the total weight of fetal livers is less than half that of the maternal liver. The combined weight of the placentas exceeds that of fetal liver, but placental glycogen is low at this late state of gestation, so that the total glycogen content of placenta is comparatively small. With glucose loading, the only glycogen store among the three organs which enlarged significantly was that of maternal liver. On the basis of chemical measurements of glycogen content it appears that fasting did not have any significant effect upon placental or fetal liver glycogen, whereas glucose loading raised only the maternal liver glycogen.

\section{Turnover of Glycogen Stores}

Table IV presents data on incorporation of labeled glucose into the three sites of glycogen storage during

Table III. Organ weight and concentration of glycogen ${ }^{1}$ at the end of infusion

\begin{tabular}{|c|c|c|c|c|c|c|c|c|c|c|c|}
\hline \multirow[b]{2}{*}{ Rat No. } & \multicolumn{2}{|c|}{ Weight of fetuses } & \multicolumn{3}{|c|}{ Fetal liver } & \multicolumn{3}{|c|}{ Placenta } & \multicolumn{3}{|c|}{ Maternal liver } \\
\hline & $\begin{array}{l}\text { Average } \\
\mathrm{g}\end{array}$ & $\begin{array}{l}\text { Total } \\
\mathrm{g}\end{array}$ & $\begin{array}{l}\text { Total } \\
\text { wt. g }\end{array}$ & $\begin{array}{l}\text { glyc. } \\
\%\end{array}$ & $\begin{array}{l}\text { glyc. } \\
\text { mg }\end{array}$ & $\begin{array}{l}\text { Total } \\
\text { wt. g }\end{array}$ & $\begin{array}{l}\text { glyc. } \\
\%\end{array}$ & $\begin{array}{l}\text { glyc. } \\
\text { mg }\end{array}$ & $\begin{array}{l}\text { Total } \\
\text { wt. g }\end{array}$ & $\begin{array}{l}\text { glyc. } \\
\%\end{array}$ & $\begin{array}{l}\text { glyc } \\
\text { mg }\end{array}$ \\
\hline \multicolumn{12}{|l|}{ A. Fasted } \\
\hline 1 & 3.67 & 55 & 4.53 & 3.23 & 146 & 7.82 & 0.42 & 33 & 10.9 & 1.14 & 124 \\
\hline 2 & 4.96 & 50 & 2.89 & 5.25 & 152 & 5.36 & 0.23 & 12 & 8.7 & 0.93 & 81 \\
\hline 3 & 4.51 & 50 & 3.20 & 3.31 & 106 & 4.93 & 0.19 & 9 & 9.7 & 1.53 & 148 \\
\hline 4 & 3.41 & 55 & 3.97 & 1.23 & 49 & 6.98 & 0.28 & 20 & 10.2 & 0.69 & 70 \\
\hline 5 & 4.65 & 79 & 4.81 & 3.82 & 184 & 7.24 & 0.13 & 9 & 12.1 & 2.10 & 254 \\
\hline 6 & 4.81 & 67 & 3.74 & 7.12 & 266 & 7.28 & 0.14 & 10 & 9.5 & 1.40 & 133 \\
\hline 7 & 4.21 & 55 & 3.13 & 5.24 & 164 & 5.68 & 0.22 & 13 & 8.6 & 1.88 & 162 \\
\hline 8 & 5.12 & 46 & 2.84 & 一 & - & 5.06 & - & 一 & 11.3 & - & - \\
\hline 9 & 4.81 & 67 & 4.79 & 2.50 & 120 & 8.05 & 0.20 & 16 & 11.7 & 0.19 & 22 \\
\hline 10 & 5.16 & 62 & 3.08 & 1.91 & 59 & 5.22 & 0.21 & 12 & 11.6 & 0.85 & 99 \\
\hline Mean & 4.53 & 58.6 & 3.70 & 3.74 & 138 & 6.36 & 0.22 & 14.9 & 10.4 & 1.19 & 122 \\
\hline$\pm \mathrm{SD}$ & \pm 0.59 & \pm 9.8 & $\pm 0.65 \pm$ & \pm 1.74 & \pm 62 & $\pm 1.15 \pm$ & \pm 0.082 & \pm 7.2 & $\pm 1.1 \pm$ & -0.56 & \pm 62 \\
\hline
\end{tabular}

B. Glucose loaded

\begin{tabular}{lrrrrrrrrrrr}
\hline 11 & 3.87 & 42 & 3.41 & 6.73 & 229 & 5.05 & 0.11 & 6 & 12.9 & 5.12 & 660 \\
12 & 6.30 & 76 & 4.41 & 6.64 & 293 & 3.68 & 0.07 & 3 & 12.9 & 4.85 & 625 \\
13 & 5.24 & 47 & 3.24 & 1.53 & 50 & 4.78 & 0.60 & 29 & 12.3 & 0.64 & 79 \\
14 & 2.52 & 35 & 2.60 & 2.00 & 52 & 5.86 & 0.57 & 33 & 11.4 & 1.15 & 131 \\
15 & 5.73 & 57 & 3.14 & 3.30 & 104 & 5.89 & 0.12 & 7 & 12.1 & 2.78 & 335 \\
\hline Mean & 4.73 & 51.5 & 3.36 & 4.04 & 146 & 5.05 & 0.29 & 15.6 & 12.3 & 2.92 & $366^{2}$ \\
$\pm \mathrm{SD}$ & \pm 0.43 & \pm 14.3 & $\pm 0.58 \pm 2.24$ & \pm 98 & $\pm 0.79 \pm 0.24 \pm 12.7$ & $\pm 0.55 \pm 1.83 \pm 242$ \\
\hline
\end{tabular}

1 Abbreviated glyc. in table

${ }^{2} \mathrm{p}<0.05$ fasted versus glucose-loaded 


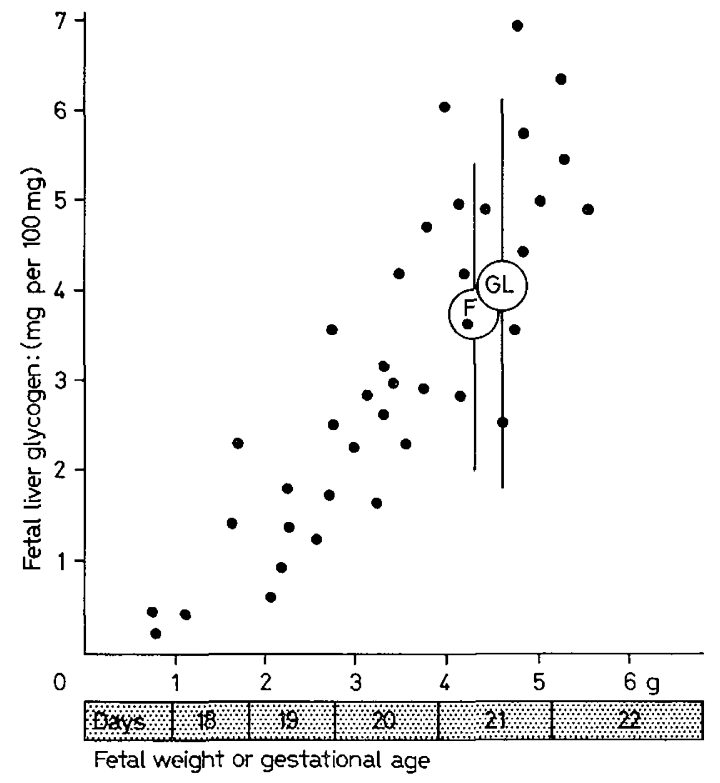

the two hours of infusion. In the fasted animals, the specific activity of glycogen was low in all three organs. For example, the specific activity of fetal liver glycogen was only about $1 / 1000$ the specific activity of fetal plasma glucose. The incorporated radioactivity was also expressed as equivalent micrograms or milligrams (in the glucose-loaded group) of glucose calculated on the basis of the specific activity of the glucose infused. This amount of incorporated radioglucose was then expressed as percent of the total glycogen present in the liver. It is apparent from these data that synthesis of glycogen from maternal glucose was negligible in fetal liver and placenta, as well as maternal liver under

Fig.2. The relation between the glycogen concentration in fetal liver and fetal weight or gestational age in pregnant rats of the same strain. The mean values for fetal liver glycogen and fetal weight of rats in the experimental groups are denoted by the circles. The brackets include two standard deviations of the mean. F equals fasted; Gl, glucose-loaded.

Table IV. Specific activity (SA) of glycogen in fetal liver, placenta and maternal liver after two hours of infusion of glucose-U-C.14

\begin{tabular}{|c|c|c|c|c|c|c|c|c|c|}
\hline \multirow[b]{2}{*}{ Rat No. } & \multicolumn{3}{|c|}{ Fetal liver glycogen } & \multicolumn{3}{|c|}{ Placental glycogen } & \multicolumn{3}{|c|}{ Maternal liver glycogen } \\
\hline & $\begin{array}{l}\mathrm{SA} \\
\mathrm{CPM} / \mu \mathrm{g}\end{array}$ & $\begin{array}{l}\mu \mathrm{g} \\
\text { equiv. }{ }^{1}\end{array}$ & $\begin{array}{l}\% \text { total } \\
\text { glycogen }\end{array}$ & $\begin{array}{l}\mathrm{SA} \\
\mathrm{CPM} / \mu \mathrm{g}\end{array}$ & $\begin{array}{l}\mu \mathrm{g} \\
\text { equiv. }\end{array}$ & $\begin{array}{l}\% \text { total } \\
\text { glycogen }\end{array}$ & $\begin{array}{l}\mathrm{SA} \\
\mathrm{CPM} / \mu \mathrm{g}\end{array}$ & $\begin{array}{l}\mu \mathrm{g} \\
\text { equiv. }\end{array}$ & $\begin{array}{l}\% \text { total } \\
\text { glycogen }\end{array}$ \\
\hline \multicolumn{10}{|c|}{ A. Fasted } \\
\hline 2 & 0.009 & 0.024 & neg. & 0.24 & 0.051 & neg. & 0.40 & 0.56 & neg. \\
\hline 4 & 0.014 & 0.017 & neg. & 0.20 & 0.10 & neg. & 0.93 & 1.6 & neg. \\
\hline 6 & 0.013 & 0.061 & neg. & 0.57 & 0.10 & neg. & 0.88 & 2.1 & neg. \\
\hline 7 & 0.030 & 0.13 & neg. & 0.13 & 0.045 & neg. & 0.56 & 2.4 & neg. \\
\hline 9 & 0.019 & 0.060 & neg. & 0.28 & 0.12 & neg. & 0.30 & 0.17 & neg. \\
\hline 10 & 0.061 & 0.095 & neg. & 0.24 & 0.076 & neg. & 0.42 & 1.1 & neg. \\
\hline $\begin{array}{l}\text { Mean } \\
\pm \mathrm{SD} \pm\end{array}$ & $\begin{array}{r}0.024 \\
\pm 0.018\end{array}$ & 0.065 & - & $\begin{array}{r}0.28 \\
\pm 0.14\end{array}$ & 0.082 & neg. & $\begin{array}{r}0.58 \\
\pm 0.24\end{array}$ & 1.3 & neg. \\
\hline
\end{tabular}

\section{B. Glucose loaded}

\begin{tabular}{|c|c|c|c|c|c|c|c|c|c|}
\hline \multirow[b]{2}{*}{11} & \multicolumn{3}{|c|}{ (mg equiv.) } & \multicolumn{3}{|c|}{ (mg equiv.) } & \multicolumn{3}{|c|}{ (mg equiv.) } \\
\hline & 0.35 & 3.8 & 1.7 & 0.12 & 0.034 & 0.6 & 1.7 & 53 & 8 \\
\hline 12 & 0.91 & 12.8 & 4.4 & 0.27 & 0.039 & 1.3 & 9.1 & 274 & 44 \\
\hline 13 & 0.34 & 1.5 & 2.9 & 0.03 & 0.075 & 0.3 & 5.0 & 34 & 43 \\
\hline 14 & 0.47 & 2.1 & 4.1 & 0.38 & 1.1 & 3.3 & 4.8 & 54 & 41 \\
\hline 15 & 0.11 & 1.0 & 1.0 & 0.18 & 0.11 & 1.6 & 2.0 & 58 & 17 \\
\hline Mean & 0.44 & 4.2 & 2.8 & 0.20 & 0.27 & 1.4 & 4.5 & 95 & 31 \\
\hline$\pm \mathrm{SD}$ & \pm 0.26 & \pm 4.4 & \pm 1.3 & \pm 0.12 & \pm 0.41 & \pm 1.0 & \pm 2.7 & \pm 90 & \pm 15 \\
\hline
\end{tabular}

1 The radioactivity appearing in glycogen has been expressed as equivalent $\mu \mathrm{g}$ or $\mathrm{mg}$ glucose based upon the specific activity of the infusions 
fasting conditions. During glucose loading, incorporation of glucose into glycogen rose significantly over that observed during fasting of all three organs. The percent of the total glycogen store which derived from the infusion was still relatively small in fetal liver $(2.8 \%)$ and placenta $(1.4 \%)$, compared to maternal liver (31\%).

From these data, it is concluded that the rate of synthesis of fetal liver glycogen is very slow in the pregnant animal during fasting. However, the rate increased with glucose loading. In the glucose-loaded group, the minimum rate of net synthesis of fetal liver glycogen was $1.4 \% / \mathrm{h}$.

\section{Discussion}

All mammalian species share a common pattern of storing hepatic glycogen just before term [18]. This store of glycogen probably serves as a source of fuel for the critical interval between interruption of transplacental nutrition and the beginning of suckling. Biochemical studies of the pattern of development of enzymes in fetal liver have not provided a completely satisfactory explanation for this accumulation of glycogen [8]. Originally, Nemeth found low levels of glucose-6-phosphatase in slices of liver from fetal guinea pigs and postulated that this block in release of free glucose led to accumulation of glycogen [17]. A similar pattern of development for this enzyme was confirmed in the rat by Weber and Ganterow [22]. However, VILLEE found adult levels of glucose-6-phosphatase in human fetal liver at midgestation [21] and DAwkins found similar levels in the liver of the fetal rhesus monkey near term [7], yet in both primate species glycogen accumulates before birth [18]. Both phosphorylase and phosphoglucomutase have been demonstrated in fetal rat liver [8] and glycogen mobilization within the fetus can be demonstrated in utero under stimuli such as anoxia [6]. Therefore, the enzymes responsible for glycogen breakdown are present in fetal liver and their absence cannot be invoked to explain an accumulation of glycogen. The enzyme necessary for glycogen synthesis, uridine diphosphoglucose-alphaglucan glucosyltransferase appears in rat fetal liver just before glycogen accumulates and increases rapidly to adult or higher levels before term [8]. Synthesis of glycogen from glucose and fructose has been demonstrated in rat fetal liver slices [7]. In the fetal rat, the enzyme glucokinase appears to be absent from liver, but glucose is actively phosphorylated through hexokinase activity [2]. Thus, the pathway for conversion of plasma glucose to glycogen in fetal liver has been demonstrated in vitro. However, the alternative pathway for synthesis of glycogen, gluconeogenesis, could not be demonstrated in rat fetal liver by BALLARD and Oliver
[1]. They found that fructose-1,6-diphosphatase, an enzyme necessary for gluconeogenesis, could not be detected in fetal rat liver, whereas it was present in fetal lamb liver. These same authors were unable to show significant incorporation of pyruvate into glycogen by slices of rat fetal liver. On the basis of these data, they have concluded that the pathway of gluconeogenesis is not operative in rat fetal liver. In apparent contradiction to this conclusion, the present studies provide evidence that the pathways for production of glucose by the liver are operative in utero and that active gluconeogenesis may be present when maternal plasma glucose falls to fasting levels. The only alternative explanation for the lower specific activity of glucose in fetal plasma compared to maternal plasma glucose is the possibility that glycogenolysis occurred during the course of the two-hour infusions or during the procedures of sacrificing the animals [5]. If glycogenolysis had occurred as an artifact of the experimental procedures, then it must be assumed that the actual fetal plasma glucose concentration before sacrifice was lower by the same relative fraction as the reduction in specific activity. The determinations of glycogen content in the various groups of infused animals compared to that of noninfused animals suggest that significant glycogenolysis did not take place during the experimental procedure. Furthermore, studies in vitro from animals sacrificed by the same techniques have shown that the spontaneous activity of phosphorylase in fetal liver slices is very low, although this activity could be stimulated by addition of epinephrine to the incubation medium [12]. In vitro studies have also shown that the pathway for gluconeogenesis from glutamic acid $\mathrm{C}^{\mathbf{1 4}}$ to glucose $\mathrm{C}^{14}$ is active in fetal liver slices from animals of comparable gestational age [12]. Taken together, these data suggest that gluconeogenesis is operative in utero in fetal liver during periods of maternal fasting. It would also appear that during these periods of relative glucose deprivation, fetal liver glycogen is not mobilized to provide fetal plasma glucose, but rather its concentration is preserved by fetal gluconeogenesis. However, in prolonged starvation of pregnant animals, fetal liver glycogen has been shown to fall [20]. During fasting in the pregnant animal, then, a competition may exist for gluconeogenetic precursors between the maternal liver, the fetal liver, and the growing fetal tissues. If fasting is of short duration, fetal liver glycogen is preserved and gluconeogenesis predominates; however, if fasting is prolonged, then glycogen is depleted. During periods of glucose excess, as represented by the glucose-loaded animals, fetal liver glycogen is synthesized at a greater rate and fetal liver gluconeogenesis is reduced ${ }^{4}$.

These studies have several clinical implications. First, the apparent reliance of the fetus upon gluconeo- 
genesis as a source of glucose during maternal fasting suggests that prolonged fasting might greatly disturb fetal intermediary metabolism. This may be particularly important if amino acids are the major gluconeogenetic precursors used by the fetal liver in synthesizing glucose, since provision of plasma glucose would then compete with protein synthesis within the fetus. On the other hand, utilization of gluconeogenesis by the fetus during periods of maternal fasting may represent a mechanism for stimulation of these pathways in preparation for extrauterine life. If a cyclic pattern of stimulation is important in development of these pathways, then inhibition of gluconeogenesis by chronic hyperglycemia as in the infant of the diabetic mother might lead to inadequate development of hepatic pathways for gluconeogenesis, thereby predisposing the infant to neonatal hypoglycemia.

\section{References and Notes}

1. Ballard, F.J. and Oliver, I.T.: Appearance of fructose 1,6-diphosphatase in postnatal rat liver. Nature (Lond.) 195: 498 (1962).

2. Ballard, F.J. and Oliver, I.T.: Ketohexokinase, isoenzymes of glucokinase and glycogen synthesis from hexoses in neonatal rat liver. Biochem.J. 90: 261 (1964).

3. Battaglia, F. C.; Hellegers, A. E.; Heller, G.J. and BEHRMAN, R.: Glucose concentration gradients across the maternal surface, the placenta and the amnion of the rhesus monkey (macaca mulatta). Amer.J. Obstet. Gynec. 88: 32 (1964).

4. Bishop, J.S.; Streele, R.; Altszuler, N.: Dunn, A.; BJerknes, C. and deBodo, R. G. : Effect of insulin on liver glycogen synthesis and breakdown in the dog. Amer.J. Physiol. $208: 307$ (1965).

5. Dawes, G.S.; Jacobson, H.N.; Motr, J.C.; Shelley, H.J. and StafFord, A.: The treatment asphyxiated, mature foetal lambs and rhesus monkeys with intravenous glucose and sodium carbonate. J. Physiol. 169: 167 (1963).

6. Dawes, G.S.; Mott, J.G. and Shelley, H.J.: The importance of cardiac glycogen for maintenance of life in foetal lambs and new-born animals during anoxia. J. Physiol. 146: 516 (1959).

7. DAwkins, M.J.R.: Glycogen synthesis and breakdown in fetal and newborn rat liver. Ann. N.Y. Acad.Sci. 111: 203 (1963).

8. DAwnins, M.J.R.: Biochemical aspects of developing function in newborn mammalian liver. Brit. med.Bull. 22: 27 (1966).

${ }^{4}$ Whether these changes in fetal liver glucose metabolism during hyperglycemia reflect the activity of fetal insulin remains to be established $[4,16]$.
9. Depocas, F.: The pool size, turnover rate, and oxidation rate of body glucose in anesthetized warm and cold-acclimated rats exposed to a warm environment. Can.J.Biochem.Physiol. 37: 285 (1959).

10. Good, C.A.; Kramer, H. and Somogyi, M.: The determination of glycogen. J. biol. Chem. 100: 485 (1933).

11. Goodner, C.J.: Studies of anterior pituitary tissue in vitro: Comparison of carbohydrate metabolism in glands from male and female rats. Endocrinology 75: 846 (1964).

12. Goodner, G.J.: Unpublished observations.

13. Holmberg, N.G.; Kaplan, B.; Karvonen, M.J.; Lind, J. and MALM, M.: Permeability of human placenta to glucose, fructose and xylose. Acta physiol.scand. 36: 291 (1956).

14. JAcQuot, R. and KRETchmer, N.: Effect of fetal decapitation on enzymes of glycogen metabolism. J. biol. Chem. 239: 1301 (1964).

15. Krm, J.N. : Effects of hyperglycemia on beta granulation in pancreatic islets of fetuses from diabetic rats. Diabetes 14: 137 (1965).

16. Madison, L.L.; Combes, B.; Adams, R. and StrickLAND, W.: The physiological significance of the secretion of endogenous insulin into the portal circulation. III. Evidence for a direct immediate effect of insulin on the balance of glucose across the liver. J. clin. Invest. 39: 507 (1960).

17. Nemeth, A.M.: Glucose-6-phosphatase in the liver of the fetal guinea pig. J. biol. Chem. 208: 773 (1954).

18. Shelley, H. J.: Glycogen reserves and their changes at birth and in anoxia. Brit. med. Bull. 17: 137 (1961).

19. Steele, R.J.; Wall, J.S.; deBodo, R.C. and Altszuler, N.: Measurement of size and turnover rate of body glucose pool by the isotope dilution method. Amer.J. Physiol. 187: 15 (1956).

20. Stuart, H.A. and Hrgarins, G.M.: Rhythmic changes in the fetal liver after feeding. Amer.J. Physiol. 111: 590 (1935).

21. VILLEE, C.A.: Regulation of blood glucose in the human fetus. J.appl. Physiol. 5: 437 (1953).

22. Weber, G. and Cantero, A.: Glucose-6-phosphatase activity in regenerating embryonic and newborn rat liver. Cancer Res. 15: 679 (1955).

23. WIDDAs, W.F.: Transport mechanisms in the foetus. Brit.med. Bull. 17: 107 (1961).

24. This investigation was supported in part by Research Grant HD 00405 and Training Grant AM 5331 from the USPHS, and Lederle Medical Faculty Award.

25. Goodner, G.J., M.D., Associate Professor of Medicine, King County Hospital, 325 9th Avenue, Seattle, Wash. 98104 (USA). 